\title{
Efficacy of Five Rotary Systems versus Manual Instrumentation During Endodontic Retreatment
}

\author{
Luiz Fernando FARINIUK ${ }^{1}$ \\ Vânia Portela Dietzel WESTPHALEN ${ }^{1}$ \\ Ulisses Xavier da SILVA-NETO ${ }^{1}$ \\ Everdan CARNEIRO ${ }^{1}$ \\ Flares BARATTO FILHO ${ }^{2}$ \\ Sandra Rivera FIDEL ${ }^{3}$ \\ Rivail Antônio Sérgio FIDEL ${ }^{3}$ \\ ${ }^{1}$ PUC - Pontifical Catholic University of Paraná, Curitiba, PR, Brazil \\ ${ }^{2}$ Positivo University, Curitiba, PR, Brazil \\ ${ }^{3} U E R J$ - State University of Rio de Janeiro, Rio de Janeiro, RJ, Brazil
}

\begin{abstract}
The purpose of this study was to evaluate the efficiency of ProFile, GT, ProTaper, Race and K3 rotary instruments compared with hand K-files for removal of gutta-percha during retreatment. Sixty mandibular premolars were instrumented with GT rotary files and filled by thermomechanical compaction of gutta-percha and AH Plus sealer. The teeth are randomly divided into 6 groups of 10 specimens each. The roots were split longitudinally, digital images were created using a flatbed scanner, and the areas with remaining filling material were demarcated using Image Tool 1.21 software. The results indicate that GT left significantly less $(\mathrm{p}<0.05)$ remaining filling material $(1.18 \pm 1.47)$ than hand $(3.70 \pm 3.16)$ and Hero instruments $(2.99 \pm 2.58)$. There was no statistically significant difference $(p<0.05)$ among the others techniques: ProFile $(1.99 \pm 2.66)$, ProTaper $(2.00 \pm 1.99)$ and K3 $(2.71 \pm 2.87)$ when compared with GT. In conclusion, GT, ProFile, ProTaper and K3 were more effective in removing gutta-percha than manual and Hero instruments.
\end{abstract}

Key Words: gutta-percha removal, nickel-titanium files, root canal retreatment, rotary instrumentation.

\section{INTRODUCTION}

Conventional root canal retreatment is one of greatest technical difficulties faced by endodontists, as filling materials represent a mechanical barrier that can often demand considerable time and effort to be removed (1). It requires regaining access to the root canal system by removal of the original filling with endodontic hand files, heat instruments, ultrasonic instruments or engine driven rotary files followed by cleaning, shaping and reobturation $(2,3)$.

The use of nickel-titanium (NiTi) rotary instruments for root filling removal and root canal retreatment has been widely investigated as a promising approach (1,3-12). An important aspect of this method is the possibility of removing the root filling material without using gutta-percha solvents (4). Eliminating the use of solvents may avoid the formation of a thin film of gutta-percha on the walls of the root canal (5). Such film might reduce the action of intracanal medicaments and the adhesion of the root canal sealer to the canal walls on the retreatment therapy. Other advantages of rotary instruments are the non-utilization of potential carcinogenic products (6) and the elimination of possible apical extrusion of gutta-percha by excessive dissolution of this material.

The aim of this study was to evaluate the efficiency of five rotary NiTi systems - ProFile, GT, ProTaper, K3 and HeRo - compared with hand instrumentation with $\mathrm{K}$-files for removal of gutta-percha from root canals.

\section{MATERIAL AND METHODS}

\section{Preparation of Specimens}

Sixty single and straight human mandibular 
premolars were selected for this study. The teeth were cleaned and stored in a 0.1 thymol solution and washed with saline at the moment of use. Radiographs were exposed from the buccolingual aspect and all teeth presented fully formed apices and similar lengths and diameters. Preparation of access cavities was made using high speed diamonds and water spray. Size $15-\mathrm{K}$ files were introduced to the canal length and the working length was established by deducting $1 \mathrm{~mm}$ from this measure, as recorded when the tip of the file was visible at the apex.

\section{Root Canal Preparation}

The coronal and middle thirds of the canal were flared with GT rotary files (Dentsply-Maillefer, Ballaigues, Switzerland) size 20 tapers $0.12,0.10$, 0.08 and 0.06 in a crown-down manner, and canal instrumentation was completed with sizes 20,25 and 30 taper 0.04 . The files were activated by an electric engine (TC Motor 3000; Nouvag, Goldach, Switzerland) at 300 rpm. Irrigation was done with $1 \%$ sodium hypochlorite during instrumentation and 17\% EDTA as a final irrigant.

\section{Root Canal Filling}

Each canal was dried with paper points and a standardized gutta-percha master cone size 30 (Tanariman, Manucapuru, AM, Brazil) was coated with sealer AH Plus (Dentsply De Trey, Konstanz, Germany) and placed at the working length. Termomechanical compaction in a hybrid technique was accomplished using Gutta-Condensor 35 (Dentsply-Maillefer) suggested by Tagger (13). Excess gutta-percha was removed and the access cavities were sealed with Cavit (Espe Dental, Medizin, Germany), radiographed and stored at $37^{\circ} \mathrm{C}$ in $100 \%$ relative humidity for 90 days to allow complete setting of the sealer.

\section{Retreatment Techniques}

A single operator carried out all retreatment procedures. The teeth were randomly assigned to 6 groups of 10 specimens each, and the canals were retreated with one of the following methods:

Group 1: ProFile 04 taper NiTi rotary instruments (Dentsply-Maillefer). The instruments were used in a crown-down manner in the following sequence: sizes $90,60,45$ and 40.
Group 2: ProTaper NiTi rotary instruments (Dentsply-Maillefer). F3 and F2 files were used in a crown-down manner with, and final apical enlargement was accomplished with F3 file.

Group 3: GT NiTi rotary instruments (DentsplyMaillefer). The instruments were used in a crown-down manner in the following sequence: $700.12,500.12,35$ 0.12 (flaring files) and final apical enlargement with 20 $0.12,35$ and 400.04 files.

Group 4: K files (Dentsply-Maillefer - control group). The files were used in a crown-down manner in the following sequence: sizes $80,70,60,55,50$, 45, 40, 35, 30, 25 files. Final apical enlargement was accomplished with sizes 30,35 and 40 files, maintaining a circumferential motion and using eucaliptol as solvent (S.S. White, Rio de Janeiro, RJ, Brazil).

Group 5: K3 NiTi rotary instruments (Sybron Dental Specialties/Kerr Corporation, Orange, CA, USA). The instruments were used in a crown-down manner in the following sequence: $400.06,350.04$ and 300.04 . Final apical enlargement was done with 35 and 400.04 file.

Group 6: Hero NiTi rotary instruments (Micro Mega, Cedex, France). The instruments were used in a crown-down manner used in the following sequence: Endo-flare, 30 0.06, 450.04 and final apical enlargement with 400.04 file.

In all groups retreated with rotary instruments, the instruments were driven by an electric engine TC Motor 3000 (Nouvag) at $300 \mathrm{rpm}$. No solvent was used in these groups. In all specimens, the filling material was removed with the aforementioned instruments according to the groups. Complete removal of the material was considered when the instrument did not carry any further filling material when inserted and removed.

\section{Evaluation of Root Canal Cleaning}

After removal of the filling material, the roots were grooved longitudinally in a buccolingual direction into two halves with a diamond disk and then split with a chisel. Each half of the root was scanned using a flatbed scanner (Genius Color-Page-HR7X Slim; KYE Systems America Corporation, Miami, FL, USA) with a standardized brightness and resolution of $600 \mathrm{dpi}$ and 48 bit. A ruler was added to each captured image, with aid of the software Microsoft Photo Editor, to divide the half in thirds, standardizing the length of each third for all specimens. The images were evaluated using Image 
Tool software version 1.21 (University of Texas Health Science Center, San Antonio, TX, USA). Measurement of the areas with gutta-percha and sealer remaining was performed with this software. The regions with remaining filling material at each third were demarcated with the mouse and the area was measured in $\mathrm{mm}^{2}$, recording the total amount of remaining filling debris in each third and in the entire root canal.

\section{Statistical Analysis}

The amount of remaining filling material according to the thirds in the groups was recorded and subjected to statistical analysis. Two-way ANOVA (full factorial model) was applied to assess if there were differences in the mean values of the remaining filing material among groups and among thirds. For application of ANOVA, the assumptions of normality and homogeneity of variances were initially tested using the Kolmogorov-Smirnov normality test and the Levene test.

When the ANOVA indicated difference in the mean values among groups and/or thirds, the Games-Howell test for multiple comparisons with non-homogeneous variance was applied. Results were processed and analyzed with the SPSS 10.0 software (Statistical Package for the Social Sciences Inc., Chicago, IL, USA).

Table 1. Mean values of remaining filling material (in $\mathrm{mm}^{2}$ ) in the groups.

\begin{tabular}{ll}
\hline Group & Mean (SD) \\
\hline ProFile & $1.99(2.66)$ \\
ProTaper & $2.00(1.99)$ \\
GT & $1.18(1.47)$ \\
Manual & $3.70(3.16)$ \\
K3 & $2.71(2.87)$ \\
Hero & $2.99(2.58)$ \\
\hline
\end{tabular}

Table 2. Mean values of remaining filling material (in $\mathrm{mm}^{2}$ ) in the root canal thirds $(n=60)$.

\begin{tabular}{ll}
\hline Root canal third & Mean (SD) \\
\hline Cervical & $4.36(2.95) \mathrm{a}$ \\
Middle & $2.27(2.10) \mathrm{b}$ \\
Apical & $0.65(0.74) \mathrm{c}$ \\
\hline
\end{tabular}

\section{RESULTS}

Remaining filling material was observed in all groups. There was statistically significant differences $(p<0.01)$ in the means of remaining filling material among groups and among thirds, without significant interaction $(p>0.05)$ between groups and thirds.

Application of the Games-Howell test on the factor remaining filling material revealed that groups GT, Manual and Hero exhibited statistically different mean values $(p<0.05)$. Table 1 displays the mean values of remaining filling material according to the groups.

There was significant difference $(\mathrm{p}<0.01)$ in the mean values of remaining filling material among all thirds (Table 2).

Analysis of the mean values of remaining filling material according to groups and thirds (Table 3 ) revealed

Table 3. Mean values of remaining filling material (in $\mathrm{mm}^{2}$ ) according to the interaction of groups and thirds.

\begin{tabular}{|c|c|c|c|}
\hline Groups & Thirds & $\mathrm{N}$ & Mean (SD) \\
\hline \multirow{3}{*}{ ProFile } & Cervical & 10 & $4.14(3.06)$ \\
\hline & Middle & 10 & $1.50(2.17)$ \\
\hline & Apical & 10 & $0.33(0.51)$ \\
\hline \multirow{3}{*}{ ProTaper } & Cervical & 10 & $3.42(2.62)$ \\
\hline & Middle & 10 & $1.81(1.22)$ \\
\hline & Apical & 10 & $0.77(0.69)$ \\
\hline \multirow{3}{*}{ GT } & Cervical & 10 & $2.20(1.62)$ \\
\hline & Middle & 10 & $1.03(1.50)$ \\
\hline & Apical & 10 & $0.32(0.39)$ \\
\hline \multirow{3}{*}{ Manual } & Cervical & 10 & $7.06(2.95)$ \\
\hline & Middle & 10 & $2.84(1.63)$ \\
\hline & Apical & 10 & $1.21(0.70)$ \\
\hline \multirow{3}{*}{ K3 } & Cervical & 10 & $4.62(3.01)$ \\
\hline & Middle & 10 & $2.86(2.82)$ \\
\hline & Apical & 10 & $0.64(0.84)$ \\
\hline \multirow{3}{*}{ Hero } & Cervical & 10 & $4.72(2.46)$ \\
\hline & Middle & 10 & $3.60(2.13)$ \\
\hline & Apical & 10 & $0.63(0.96)$ \\
\hline
\end{tabular}


that group GT exhibited the best outcomes at the cervical, middle and apical thirds. This group was statistically different from groups Manual and Hero, but did not differ significantly from groups ProFile, ProTaper and K3.

\section{DISCUSSION}

Root canal retreatment is one of the most difficult and time-consuming endodontic procedures. Removal of the filling material is fundamental for reshaping of the root canal system and for achievement of the desired goals in canal therapy (2).

Several studies have been conducted to develop and investigate new instruments that provide clean, debris-free, disinfected root canal system (14). The use of NiTi rotary instruments has been indicated for this purpose and it has been demonstrated that they may provide a tapered root canal with minimum risk of irregularities and canal transportation, requiring less operative time than manual instrumentation (15). Although the use of rotary instrumentation is easier and faster, effective cleaning of the entire root canal system is still a challenge (16).

In earlier retreatment studies, remaining guttapercha was assessed radiographically $(8,11,12)$ or residual gutta-percha were measured using evaluation scales, e.g. severe, moderate, mild or no-retreatment debris $(1,4,17,18)$. In the present study, the roots were split longitudinally and the residual filling material was measured linearly. Delineation of the remaining filling material with aid of softwares is more precise than the utilization of scores $(1,7,9,10,18-20)$. This precision is related to image magnification on the computer, providing better quality of images.

Solvents were not used with rotary instruments because previous data have shown that canals that were not cleaned with solvents presented better cleaning (6). In addition, the frictional heat generated by rotary instruments may soften the gutta-percha and this way the working length is easily reached, and rotary instruments are designed for removal of materials in apicocoronal direction during their use.

In all groups, apical file size was 40 except for ProTaper group in which the last instrument used was $\mathrm{F} 3$, because at the moment of this study it was the last instrument in the series.

Regarding the total amount of remaining guttapercha in the entire root canal or in each third, group GT exhibited the best results, with significant difference when compared with the Manual and Hero groups. Although group GT presented the best results when compared with groups ProFile, ProTaper and K3, there were no significant differences among them with respect to their cleaning efficiency.

The results of the present study disagree with those of Hülsmann and Bluhm (9), who found that GT rotary instruments are unable to cut the filling material because they have radial-land and U-shaped transverse section. Other authors (19) also reported the higher cutting efficacy of instruments as FlexMaster or Hedströem files compared with ProFile and GT rotary file systems.

The evaluation by thirds revealed a greater amount of remaining filling material at the cervical third, followed by the middle and apical thirds. This is in agreement with the findings of Masiero and Barletta (8), who reported that rotary instruments leave a smaller amount of filling material at the apical third because they assign a round shape to the root canal. In the present study, group ProTaper exhibited better cleaning at the cervical third than group ProFile, which has larger instruments. This may be related to the design, negative cutting angle and convex diameter of these instruments (9), which have high capacity of removing filling material. Some difficulty was felt in the initial penetration into the filling material, due to the small diameter of these instruments. The use of ProTaper instruments required a higher pressure to remove the filling material when compared with other instruments.

Several authors agree that complete removal of filling material from the root canals with rotary instruments is not possible $(1,4,18)$ and there is the need complementing cleaning with hand files, although rotary instrumentation is much faster $(4,17)$.

Considering the advances in the available technology, further studies should be conducted to investigate new instruments and devices, willing to enhance the daily endodontic practice and provide safer and more reliable treatments.

Based on the present methodology and obtained results, the following conclusions may be drawn: 1 . None of the techniques investigated provided complete removal of filling material from the root canals; 2 . The instruments investigated may be arranged in the following increasing order of efficacy in removing filling debris: Manual, Hero, K3, ProTaper, ProFile and GT; 3. Comparing the thirds, the apical third exhibited the smallest amount of remaining filling material, followed by the middle and cervical thirds. 


\section{RESUMO}

O propósito deste estudo foi avaliar a eficiência dos instrumentos rotatórios ProFile, GT, ProTaper, Race e K3 comparados com limas $\mathrm{K}$ para a remoção do material obturador durante o retratamento. Sessenta pré-molares inferiores foram instrumentados com o sistema rotatório GT e obturados usando a técnica de compactação termomecânica de guta-percha com cimento AH Plus. Os dentes foram divididos aleatoriamente em seis grupos de dez espécimes cada. As raízes foram seccionadas longitudinalmente, imagens digitais foram criadas através de um scanner, e as áreas de remanescentes de material foram medidas usando o programa Image Tool 1.21. Os resultados indicaram que o GT deixou significantemente menos material remanescente $(1,18 \pm 1,47)$ do que os instrumentos manuais $(3,70 \pm 3,16)$ e os instrumentos Hero $(2,99 \pm 2,58)(p<0,05)$. Não houve diferença estatisticamente significante entre as outras técnicas ProFile $(1,99 \pm 2,66)$, ProTaper $(2,00 \pm 1,99)$ e K3 $(2,71 \pm 2,87)$ quando comparadas com o GT. Como conclusão, GT, ProFile, ProTaper e K3 foram revelados como mais efetivos em remover a guta-percha do que os instrumentos manuais e os instrumentos Hero.

\section{ACKNOWLEDGEMENTS}

The authors express their sincere appreciation to Professor Sérgio Inácio for his extensive help with the statistical analysis.

\section{REFERENCES}

1. Baratto-Filho F, Ferreira EL, Fariniuk LF. Efficiency of the 0.04 taper ProFile during the re-treatment of gutta-percha-filled root canals. Int Endod J 2002;35:651-654.

2. Stabholz A, Friedman S. Endodontic retreatment - case selection and technique. Part 2: Treatment planning for retreatment. J Endod 1988;14:607-614.

3. Schirrmeister JF, Wrbas KT, Schneider FH, Altenburger MJ, Hellig E. Effectiveness of a hand file and three nickel-titanium rotary instruments for removing gutta-percha in curved root canals during retreatment. Oral Surg Oral Med Oral Pathol Oral Radiol Endod 2006;101:542-547.

4. Sae-Lim V, Rajamanickam I, Lim BK, Lee HL. Effectiveness of ProFile .04 taper rotary instruments in endodontic retreatment. J Endod 2000;26:100-104.

5. Wilcox LR, Krell KV, Madison S, Rittman B. Endodontic retreatment: evaluation of gutta-percha and sealer removal and canal reinstrumentation. J Endod 1987;13:453-457.
6. Tamse A, Unger U, Metzger Z, Rosenberg M. Gutta-percha solvents - a comparative study. J Endod 1986;12:337-339.

7. Kosti E, Lambriandinis T, Economides N, Nofitou C. Ex vivo study pf the efficacy of $\mathrm{H}$-files and rotary $\mathrm{Ni}-\mathrm{Ti}$ instruments to remove gutta-percha and four types of sealer. Int Endod J 2006;39:48-54.

8. Masiero AV, Barletta FB. Effectiveness of different techniques for removing gutta-percha during retreatment. Int Endod J 2005;38:27.

9. Hülsmann M, Bluhm V. Efficacy, cleaning ability and safety of different rotary $\mathrm{NiTi}$ instruments in root canal retreatment. Int Endod J 2004;37:468-476.

10. Duarte MAH, Reis Só MV, Cimadon VB, Zucatto C, Vier-Pelisse FV, Kuga MC. Effectiveness of rotary or manual techniques for removing a 6 year old filling material. Braz Dent J 2010;21:148152.

11. Gergi R, Sabbagh C. Effectiveness of two nickel-titanium rotary instrtuments and a hand file for removing gutta-percha in severely curved root canals during retreatment: an ex vivo study. Int Endod J 2007;40:532-537.

12. Carvalho Maciel AC, Zacaro Scelza MF. Efficacy of automated versus hand instrumentation during root canal retreatment: na ex vivo study. Int Endod J 2006;39:779-784.

13. Tagger M, Tamse A, Katz A, Korzen BH. Evaluation of the apical seal produced by a hybrid root canal filling method, combining lateral condensation and thermatic compaction. J Endod 1984;10:299-303.

14. Gambarini G. Shaping and cleaning the root canal system: a scanning electron microscopic evalution of a new instrumentation and irrigation technique. J Endod 1999;25:800-803.

15. Fariniuk LF, Baratto-Filho F, Guerisoli DMZ, Barbizam JVB, Pécora JD, Sousa-Neto MD. Modeling capacity of ENDO flash files in simulated root canals. Braz Dent J 2001;12:39-42.

16. Siqueira JR JF, Araújo MCP, Garcia PF, Fraga RC, Sabóia Dantas CJ. Histological evaluation of effectiveness of five instrumentation techniques for cleaning the apical third of root canals. J Endod 1997;23:499-502.

17. Ferreira JJ, Rhodes JS, Ford TR. The efficacy of gutta-percha removal using ProFiles. Int Endod J 2001;34:267-274.

18. Hülsmann M, Stotz S. Efficacy, cleaning ability and safety of different devices for gutta-percha removal in root canal retreatment. Int Endod J 1997;30:227-233.

19. Imura N, Kato AS, Hata GI, Uemura M, Toda T, Weine F. A comparison of the relative efficacies of four hand and rotary instrumentation techniques during endodontic retreatment. Int Endod J 2000;33:361-366.

20. Zmener O, Pameijer CH, Banegas G. Retreatment efficacy of hand versus automated instrumentation in oval-shaped root canals: an ex vivo study. Int Endod J 2006;39:521-526.

Received April 20, 2010 Accepted March 28, 2011 